\title{
An exploration into Penultimate and Final Lengthening in Tswana (Southern Bantu)
}

\author{
Fabian Schubö ${ }^{1}$ \\ Institute of Linguistics, University of Stuttgart, Germany \\ E-mail: fabian.schuboe@ifla.uni-stuttgart.de
}

\section{Ian Bekker}

School of Languages, North-West University, South Africa

Rigardt Pretorius

School of Languages, North-West University, South Africa

Valencia Wagner

SADiLaR, North-West University, South Africa

Sabine Zerbian ${ }^{1}$

Institute of Linguistics, University of Stuttgart, Germany

E-mail: sabine.zerbian@ifla.uni-stuttgart.de

\begin{abstract}
This study investigates the segmental lengthening patterns resulting from prosodic boundaries in Tswana, a Southern Bantu language. The aim is to shed light on the interaction between Penultimate Lengthening and Final Lengthening, providing the first quantitative investigation of these phenomena in Tswana. We conducted a production experiment that applies a widely tested design to elicit production data of two different prosodic phrasing patterns in coordinated noun phrases. The results suggest that Penultimate Lengthening and Final Lengthening constitute independent mechanisms which both apply in Tswana. Penultimate Lengthening occurs before prosodic phrase boundaries as well as before word boundaries but to differing degrees (cf. Cole 1955: 55). Before prosodic phrase boundaries, it involves a strong lengthening effect on the vowel of the penultimate syllable. Before word boundaries, the amount of lengthening is smaller. Final Lengthening operates on the final syllable before a prosodic phrase boundary, involving a larger amount on the final vowel than on the preceding consonant. This pattern is in line with the pattern observed in other languages. The amount of lengthening on the final vowel is comparable to the amount on the penultimate vowel. Given that a large
\end{abstract}

\footnotetext{
${ }^{1}$ Corresponding author.
} 
increase of lengthening on the penultimate syllable has not been observed in connection with Final Lengthening, we assume that Penultimate Lengthening constitutes a language-specific mechanism that applies independently. Final Lengthening, on the other hand, might be a universal phenomenon. The perceptual salience of Penultimate Lengthening, which has been widely reported in the literature for Bantu languages, might have to do with the dynamics within the lengthening domains, namely that the lengthening in penultimate position is relatively stronger than in final position when compared to the preceding syllable.

Keywords: Tswana; duration; prosodic phrasing; Final Lengthening; Penultimate Lengthening

\section{Introduction}

In Bantu languages, prosodic phrasing has been shown to be relevant for syntactic structure and information structure. In the area of syntax, prosodic phrasing has been investigated in connection with dislocations (see Downing 2011 for an overview), adverbs (see Cheng and Downing 2014 for Zulu), and relative clauses (see Cheng and Downing 2007 for Zulu, and Downing and Mtenje 2011 for Chichewa), to name some examples. In the area of information structure, prosodic phrasing has been investigated in connection with focus and topic (see Downing and Hyman 2016 for an overview). For focus, it has been generalised that the "prosodic marking of focus in Bantu languages involves the establishment of focus-related phrasal domains that are only indirectly conditioned by focus" (Downing and Hyman 2016, section 41.3.3). Also, topicalisation might induce changes in prosodic phrasing, and it has been suggested that differences in prosodic phrasing of left-peripheral topics might well provide cues to differential status as internal and external topics (see Cheng and Downing 2009 for Zulu).

A salient cue to prosodic phrasing in many Bantu languages is lengthening of a phrasepenultimate vowel (see Hyman 2013 for an overview). Next to Penultimate Lengthening (PL), Final Lengthening (FL; also called "pre-boundary lengthening") is a supposedly universal cue for indicating prosodic phrase boundaries, where material immediately preceding a boundary is lengthened (see below for further discussion).

Most phonological studies address prosodic phrasing and the theoretical modelling of prosodic phrase boundaries (e.g., Cheng and Downing 2009 and Downing 2011 for dislocated NPs, and Cheng and Downing 2014 for adverbs). However, Downing and Pompino-Marschall (2013) report on an elicited production experiment in Chichewa which measured the length of penultimate and final syllables at word and phrase boundaries under differing focus conditions. In this article, we present results from a pilot study conducted to explore the phonetic implementation and interplay of the two lengthening domains in Tswana, a Southern Bantu language. The article will start with a literature review in section 2 on PL, FL, and Tswana phonology. The research questions are presented in section 3. Section 4 outlines the methods, and section 5 presents the results. Finally, section 6 provides a discussion and ends with some concluding remarks. 


\section{Lengthening in Tswana}

\subsection{Penultimate Lengthening (PL)}

Next to tonal alternations, PL is a well-described boundary cue in many Bantu languages (see Hyman 2013 for an overview). It refers to the lengthening of the penultimate syllable of a prosodic phrase-final word in a declarative sentence. The perceptual relevance of PL has been tested in the Southern Bantu language of Xhosa: experimental data showed that the presence of $\mathrm{PL}$ is decisive for distinguishing a declarative sentence from a "yes/no"-question (Jones, Louw and Roux 2001a, 2001b). Hyman and Monaka (2011) provide a detailed description of the contexts of sentence-final PL in the Tswana variety of Shekgalagari.

However, the exact phonetic domain of PL (whether penultimate vowel or syllable; syllables are open in Bantu languages) has not been made subject to investigation. This being said, there is empirical evidence for a lengthening effect of the penultimate vowel in the Eastern Bantu language of Chichewa (e.g., Downing and Pompino-Marschall 2013) and the penultimate syllable in the Southern Bantu language of Zulu (Zeller, Zerbian and Cook 2017).

Furthermore, the phonological domain in which PL applies is subject to discussion across different languages. PL might apply both at Intonation Phrase edges as well as Phonological Phrase edges (cf. Kanerva 1990 for Chichewa, Downing and Pompino-Marschall 2013), possibly with a relatively smaller amount in the latter case.

\subsection{Final Lengthening (FL)}

Prior research suggests that prosodic boundary marking is a universal function (Carlson, Hirschberg and Swerts 2005). One central cue of boundary marking is the lengthening of material immediately preceding the boundary, referred to as "(phrase-)final lengthening" or "pre-boundary lengthening". Generally speaking, FL refers to the "phenomenon whereby segments immediately before certain linguistic boundaries are longer than segments earlier in the utterance" (Gussenhoven and Rietveld 1992: 283). This phenomenon has been found to be a stable correlate of prosodic demarcation across languages (see, e.g., Katsika 2016 for Greek; Schubö and Zerbian 2020 for German; Seo, Kim, Kubozono and Cho 2019 for Japanese; Turk and Shattuck-Hufnagel 2007 for American English), and it has been suggested that FL might be a universal tendency in speech production (see, e.g., Lindblom 1968, 1978; see Vaissière 1983 for an overview). Yet, it has also been shown that FL is implemented in language-specific ways and thus must be learnt by speakers (e.g., Nakai, Kunnari, Turk, Suomi and Ylitalo 2009 for Northern Finnish). That is, for example, FL cannot be solely attributed to a physiological effect involving the general relaxation of speech gestures towards the end of a prosodic phrase (as suggested by Lindblom 1968, amongst others); we need to assume that it results from a mechanism that speakers acquire based on their exposure to speech. To our knowledge, FL has not been investigated empirically in Bantu languages so far (for FL in Shekgalagari, see below).

One major difference regarding the implementation of FL in different languages is its point of initiation. Most empirical studies on FL only investigated the final syllable preceding the boundary, however, some studies also tested the duration of earlier syllables. These latter studies found that FL initiation can occur on the penultimate or even on the antepenultimate syllable of the phrase-final word (e.g., Berkovits 1994 for Hebrew, Cambier-Langeveld 1997 for Dutch, 
Krull 1997 for Estonian, Silverman 1990, Schubö and Zerbian 2020 for German, Seo et al. 2019 for Japanese, Turk and Shattuck-Hufnagel 2007 for American English, White 2002 for British English). In studies on stress languages, such as English and Dutch, the initiation of FL on the pre-final syllables has been attributed to the last position of main word stress preceding the boundary, suggesting a connection between FL and the word-prosodic system of the language.

As for the amount of FL, various studies found a pattern of progressive lengthening towards the end of the prosodic phrase (e.g., Cambier-Langeveld 1997 for Dutch, Schubö and Zerbian 2020 for German, Seo et al. 2019 for Japanese, Turk and Shattuck-Hufnagel 2007 for American English). That is, the amount of lengthening progressively increases from one segment to the next as the prosodic boundary is approached, so that the largest amount occurs on the final segment. Furthermore, it has been observed that the amount of lengthening drastically increases on the nuclear vowel of the final rime, independent of the rime-internal structure, whereas the preceding segments comprise a comparatively small amount of lengthening (e.g., Schubö and Zerbian 2020 for German, Seo et al. 2019 for Japanese, Turk and Shattuck-Hufnagel 2007 for American English). This suggests that the prosodic structure of the phrase-final word does not only affect the initiation of FL, but also the relative amount across the affected segments.

\section{$2.3 \quad$ Tswana}

Tswana is a Southern Bantu language spoken in South Africa and Botswana, and belongs to group S30. For a sketch of its phoneme inventory, see for example Bennett, Diemer, Kerford, Probert and Wesi (2016). Note that vowel length is not phonemic. Tswana uses tone for marking lexical and grammatical distinctions. There are two surface level tones: high and low. High tones are the active tones initiating tonal processes, such as high tone spread (e.g., Creissels 1998; see Zerbian 2017 for an overview).

Zerbian (2017) suggests the distinction between the Phonological Phrase and the Intonation Phrase in Tswana: the former shows partial reset of high tones across a boundary whereas the latter shows such a reset pattern in combination with a boundary tone and PL. PL is absent at the end of certain sentence types (see Hyman and Monaka 2011 for an overview).

However, durational patterns have not yet been investigated empirically, and the very clear perception of PL on final words in declarative sentences might not contradict a lesser amount of PL on phrase-final words within utterances. Cole (1955: 55) notes a "half length" in the penultimate syllable of every word (next to "full length" at sentence boundaries), supporting a gradual difference in length between word and phrase boundaries. Sentence-medial phrase boundaries have been reported for members of the Sotho-Tswana group - for example, before right-dislocated elements in Northern Sotho (Zerbian 2007) or before locatives in Tswana (Zerbian 2011), to name a few.

\section{Research questions}

FL has not been investigated empirically in Bantu languages comprising PL, such as Tswana. Hyman and Monaka (2011) observe FL instead of PL in paused lists in the Tswana variety of Shekgalagari. However, this can also be interpreted as a noticeable absence of PL in these cases together with a salient lengthening, rather than the confirmation of the absence of FL in all the other contexts in which PL occurs. Thus, it remains unclear if FL conventionally co-occurs with 
PL in Tswana. The fact that both FL and PL are boundary-related lengthening effects raises the question as to whether they are independent phenomena or derive from the same mechanism. PL might constitute a form of FL that ceases already on the penultimate syllable and thus shows a large amount of lengthening on the penultimate syllable rime. If, on the other hand, FL was found to apply on the final syllable in addition to PL, we may assume that the two phenomena are independent. These possibilities were tested in the framework of a production study on Tswana, which is reported on below.

The present study thus addresses the following set of research questions with regard to the patterns of boundary-related lengthening in Tswana:

(1) a. How is lengthening preceding a prosodic phrase boundary implemented on the penultimate syllable? Which segments of the penultimate syllable are affected by lengthening, and what is the amount of lengthening for each affected segment?

b. Does lengthening also occur on the final syllable preceding a prosodic phrase boundary? If so, which segments of the final syllable are affected by lengthening, and what is the amount of lengthening for each affected segment?

c. If lengthening occurs on the penultimate and the final syllables, does the overall lengthening pattern suggest two independent mechanisms (relating to PL and FL, respectively)?

Furthermore, the present study offers a preliminary exploration of lengthening at the word level, thus also comparing the duration of vowels in penultimate and final position in words that were not produced immediately preceding a prosodic phrase boundary. This is supposed to provide first insights with regard to the claim that PL also occurs at the word level, as reported, for example, by Cole (1955). The analysis is restricted to vowels, as stated in the following research question:

(2) Do vowels in the penultimate syllable have a longer duration than vowels in the final syllable when produced in phrase-medial position?

\section{Methods}

\subsection{Experiment design}

We conducted a production study that involved a well-established elicitation method for prosodic boundaries in languages like English and German (e.g., Kentner and Féry 2013; Petrone, Truckenbrodt, Wellmann, Holzgrefe-Lang, Wartenburger and Höhle 2017; Turk and Shattuck-Hufnagel 2007). The stimuli comprised lists of three proper names coordinated by the conjunctions "or" (kgotsa in Tswana) and "and" (le in Tswana). Such lists allow for either a left-branching structure, as illustrated in (2a), or a right-branching structure, as illustrated in (2b). The sentences in (3) are examples from Tswana with the corresponding structure. ${ }^{2}$ Prior studies on English and German employing such a design found that speakers use prosodic phrasing for structural disambiguation, inserting a phrase boundary after N2 in the leftbranching case (2a) and after N1 in the right-branching case (2b) (see, e.g., Petrone et al. 2017

\footnotetext{
${ }^{2}$ This is an example from Tswana as spoken in Botswana. The translation and a suggestion for phrasing was kindly provided by Boikanyego Sebina.
} 
for German). Several consultations with native speakers of Tswana suggested that such structures are well-formed in Tswana and that prosodic phrasing constitutes a means of resolving the ambiguity.

(2) $\quad$ a. $[\mathrm{N} 1$ or $\mathrm{N} 2]$ and $[\mathrm{N} 3]$

b. [N1] or [N2 and N3]

$\begin{array}{llll}\text { a. } & {[\text { Katlego }} & \text { kgotsa Naledi] le } & \text { [Lorato] } \\ \text { b. } & {[\text { Katlego }]} & \text { kgotsa [Naledi le } & \text { Lorato] } \\ & \text { Katlego } & \text { or Naledi and } & \text { Lorato } \\ & \text { 'Katlego or Naledi and Lorato' } & \end{array}$

Twelve lists of the type in (2/3) were constructed. The target words were exclusively in position N2 (i.e. the middle name). Each list was embedded in a carrier sentence, which was preceded by a short context story. An example item is given in (4). The respective branching structure was indicated by setting the object in bold and underlining the respective constituents. We created 12 items of this sort, employing eight trisyllabic proper names (Naledi, Lorato, Lesedi, Tshenolo, Kopano, Karabo, Thapelo, and Bonolo) and four disyllabic proper names (Thabo, Kano, Khumo, and Modi). All target words comprised CV syllables in penultimate and final positions. The entire set of items is given in the appendix. ${ }^{3}$

(4) Dineo o rulaganya moletlo wa letsatsi la gagwe la matsalo. O setse a laleditse ditsala dingwe. Jaanong o ipotsa gore ke mang yo mongwe gape yo a ka mo laletsang. Dineo o a nagana:

'Dineo is celebrating his birthday. He has already invited many friends. Now he is wondering who else he would like to invite. Dineo is thinking:'
a. Ke tla laletsa Katlego kgotsa Naledi le Lorato.
b. Ke tla laletsa Katlego kgotsa Naledi le Lorato.
I FUT invite Katlego or Naledi and Lorato
'I will invite Katlego or Naledi and Lorato.'

\subsection{Participants and procedure}

Eight native speakers of Tswana in their twenties and thirties ( 6 male, 2 female) participated in the experiment, all of whom were first-year students of Tswana at North-West University, Potchefstroom Campus. The contexts and target sentences were presented to the participants on a printed sheet of paper. The participants were instructed to first familiarise themselves with the given context and target sentence and then produce the target sentence in such a way that the indicated meaning was conveyed to the experimenter. Each target sentence was presented once with the left-branching structure $(3 \mathrm{a} / 4 \mathrm{a})$ and once with the right-branching structure $(3 \mathrm{~b} / 4 \mathrm{~b})$ with a filler sentence interspersed. The productions were audio-recorded with stereo sound, $44.1 \mathrm{kHz}$ sampling frequency, and a 16-bit resolution. The recordings took place at North-West University, Potchefstroom campus, in the Linguistics Lab or in a quiet office room. Each participant produced 24 target sentences ( 12 items $* 2$ conditions), which yielded a total of 192 recorded productions ( 24 target sentences $* 8$ participants).

\footnotetext{
${ }^{3}$ See Bennett et al. (2016) for details on grapheme-phoneme correspondence in Tswana.
} 


\subsection{Data analysis}

The data from two of the eight participants were excluded from the analysis because these speakers produced the same prosodic pattern across both conditions, leaving it unclear whether they had fully understood the ambiguity in the sentences. Furthermore, 10 productions from the remaining six speakers were excluded due to hesitations or unclear repetitions. Thus, altogether, 134 target productions entered the analysis.

As a first step, we performed a qualitative analysis of the prosodic phrasing patterns in the 134 productions that entered the analysis. The first and the last author listened to the sentences independently and annotated them for prosodic phrase boundaries in the sequence of nouns, paying attention to phrasing cues such as pauses and pitch reset. There was agreement on the phrasing annotations in 133 instances (99.3\%). The case in which the two authors disagreed was included in the analysis in compliance with the annotations of the last author. The quantitative analysis was performed on a subset of the data that comprised the expected phrasing patterns (see section 5 for details). The target words were manually annotated with regard to the segment boundaries of the onset consonant and nuclear vowel of the penultimate and final syllables. The segment boundaries were detected based on spectrographic and waveform information, using the acoustics analysis software Praat (Boersma and Weenink 2019). The duration values of the resulting segment intervals were extracted using an automated procedure.

The procedure for segment boundary detection followed the guidelines of Turk, Nakai and Sugahara (2006), which suggest that segment boundaries are determined by consonantal constrictions (and not by voicing criteria), coinciding with abrupt spectral changes. Figure 1 below shows a spectrogram for a production of the target word Naledi with annotations of the segment boundaries, phones, and duration values in milliseconds (ms). For completeness, the intervals for the segments of the antepenultimate syllable were included, which were not part of the present investigation. The spectrogram displays clearly visible spectral changes at all segment boundaries. Vowel boundaries were identified based on the abrupt onset and offset of formant energy, primarily relying on F2, in combination with landmarks for consonantal constrictions. Boundaries between nasal stops and vowels showed an abrupt change in formant energy, which often occurred in combination with a sudden impulse caused by the closure or release gesture. The duration of oral stops was defined by their closure phase, that is, the time period between the closing and the release gesture. As illustrated in Figure 1, the closure phase involved a low amount of energy (except for the voice bar) and could thus be detected reliably. In the case of aspirated oral stops, the aspiration phase was excluded from the measurement (see Turk et al. 2006) so that the duration of aspirated and unaspirated oral stops remained comparable. Liquids, the boundaries of which can be difficult to detect in a spectrogram, also showed clear points of demarcation. As is visible from Figure 1, the lateral approximant involved a considerably lower amount of energy in comparison with the surrounding vowels and was regularly bounded by a sudden impulse resulting from the contact and release of the tongue with the alveolar ridge. The rhotic was realised as an alveolar trill, which showed an abrupt decrease of energy between the end of the vowel and the occurrence of the first impulse resulting from the intermittent contacts of the tongue with the alveolar ridge. The beginning of the following vowel involved an abrupt onset of formant energy, sometimes preceded by a low amount of energy after the last impulse from the trill. 


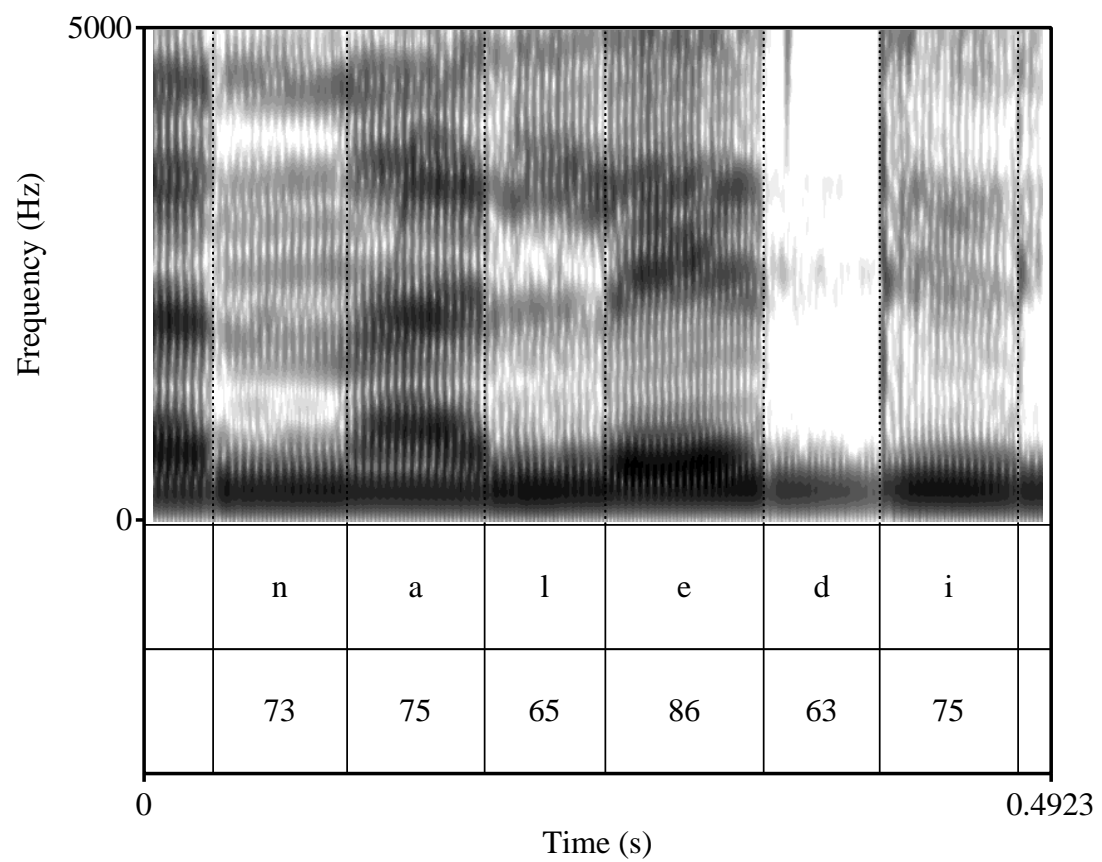

Figure 1. Spectrogram and annotations of segment information for a production of the target word Naledi in the right-branching condition by a female speaker; boundary labels indicate segment boundaries, the upper tier shows the segment transcriptions, and the lower tier shows the segment duration values in milliseconds

The end of a vowel followed by a pause was detected based on the abrupt cease of F2 energy in the majority of instances. F1 was ignored in this context because it often continues after the offset of energy in the higher frequency range so that it is less reliable for segment boundary detection (see Turk et al. 2006). In five instances, the vowel followed by a pause was only weakly voiced, but an F2 pattern could still be detected, the offset of which was taken as marking the boundary. In two further instances, the vowel followed by the pause was completely devoiced, which made the detection of the boundary more difficult. As formant patterns were not available in these cases, the boundary between the vowel and the pause was annotated at a point of abrupt decline of amplitude.

\section{Results}

\subsection{Prosodic phrasing patterns}

The qualitative analysis of the presence/absence of prosodic boundaries in the sequence of nouns revealed the prosodic phrasing patterns summarised in Table 1 (round brackets indicate perceived prosodic phrase boundaries). The table illustrates that we identified a variety of different prosodic phrasing patterns for the target structures, especially with respect to the conjunction kgotsa ('or'). As the prosodic phrasing patterns of the sequence of nouns are of primary interest for the current study, we differentiated between patterns where two of the three nouns are phrased together (i.e. either $\mathrm{N} 1$ and $\mathrm{N} 2$ or $\mathrm{N} 2$ and $\mathrm{N} 3$ ), and patterns where no grouping of nouns is found (i.e. N1, N2, and N3 are either phrased together or are phrased separately). Thus, Table 1 shows how far the perceived prosodic phrasing patterns match the given syntactic structure. 
Table 1: Frequency of perceived prosodic phrasing patterns for the left-branching and the rightbranching structures, grouped by type of prosodic phrasing; round brackets indicate perceived prosodic phrase boundaries, and square brackets indicate syntactic constituent structure (total $n=134$ )

\begin{tabular}{llc}
\hline Prosodic phrasing pattern & $\begin{array}{c}\text { Left-branching structure } \\
{[\mathrm{N} 1 \text { kgotsa N2] le [N3] }}\end{array}$ & $\begin{array}{c}\text { Right-branching structure } \\
\text { [N1] kgotsa [N2 le N3] }\end{array}$ \\
\hline
\end{tabular}

N1 and N2 phrased together:

\begin{tabular}{lcc} 
N1 kgotsa N2) (le N3 & $\mathbf{3 3}(\mathbf{4 9 \%})$ & $\mathbf{5}(\mathbf{7 . 5 \%})$ \\
\hline N2 and N3 phrased together: & $2(3 \%)$ & $23(34 \%)$ \\
N1 kgotsa) (N2 le N3 & $5(7.5 \%)$ & $14(21 \%)$ \\
N1) (kgotsa N2 le N3 & $1(1.5 \%)$ & $8(12 \%)$ \\
N1) (kgotsa) (N2 le N3 & $\mathbf{8}(\mathbf{1 2 \%})$ & $\mathbf{4 5}(\mathbf{6 7 \%})$ \\
& & $8(12 \%)$ \\
No grouping of nouns: & $18(27 \%)$ & $8(12 \%)$ \\
N1 kgotsa N2 le N3 & $5(7.5 \%)$ & $\mathbf{1 6}(\mathbf{2 4 \%})$ \\
N1) (kgotsa N2) (le N3 & $\mathbf{2 3}(\mathbf{3 4 . 5 \% )}$ & $1(1.5 \%)$ \\
& $3(4.5 \%)$ & $67(100 \%)$ \\
\hline Other: & $67(100 \%)$ & \\
Total: & &
\end{tabular}

Each word in the lists is found to be followed by a prosodic phrase boundary in some pattern except for the conjunction le ('and'), which is always phrased together with N3. This conjunction might be a proclitic, attaching to $\mathrm{N} 3$ and thus ruling out the possibility of a prosodic phrase boundary in this position. ${ }^{4}$ Phrasing patterns without grouping of the nouns are observed in one-third of the left-branching structures. They also occur with right-branching structures, but to a lesser extent. Most notably, and in accordance with prosodic phrasing patterns in other languages, in nearly half of the left-branching structures, N1 and N2 are phrased together in one prosodic phrase. In two-thirds of the right-branching structures, N2 and N3 are phrased together. Thus, we find either a phrasing without any grouping, or the predicted phrasings in which the syntactically-branching structures occur in the same prosodic phrase. Against this background, we will proceed in section 5.2 with the quantitative analysis of the implementation of boundary-related lengthening in Tswana.

In the annotation of the prosodic phrase boundaries, the annotators paid attention to cues like pauses and pitch reset. These cues occur at boundaries of both Phonological Phrases and Intonation Phrases in Tswana (Zerbian 2017). We did not specify the boundary cues any further - for example, regarding boundary tones and the relative amount of PL - thus not

\footnotetext{
${ }^{4} \mathrm{We}$ are grateful to an anonymous reviewer for pointing this out to us. The assumption that $l e$ constitutes a proclitic is also supported by tonal evidence (Creissels 1998).
} 
pre-determining the phrase level in question. This approach allows for both types of prosodic phrases to be included in the analysis. Despite the presence of long pauses in many instances, the prosodic cues observed by the annotators suggest that the prosodic phrases under investigation here are best characterised as Phonological Phrases. A more detailed analysis would be required in order to decide which of the two prosodic categories is at hand in each production. However, nothing in the following hinges on the level of prosodic phrasing and we will therefore continue to use the more general term "prosodic phrase".

\subsection{Lengthening before prosodic phrase boundaries}

The durational analysis included all pairs of sentences produced by the same speaker, with the presence/absence of a prosodic phrase boundary after the target word according to our predictions. That is, they comprised a boundary after N2 in the left-branching condition, but not in the right-branching condition. Across subjects, there were 25 such pairs. The results are presented in Figure 2. The plots for the segments of the penultimate syllable are labelled as $\mathrm{C} 1$ and $\mathrm{V} 1$, where $\mathrm{C} 1$ refers to the onset consonant and $\mathrm{V} 1$ to the vowel of the penultimate syllable. Accordingly, the plots for the segments of the final syllable are labelled as $\mathrm{C} 2$ and V2, where C2 refers to the onset consonant and V2 to the vowel of the final syllable. The plots suggest that the onset consonants and the following vowels in both syllables are longer in phrase-final position (green) than in phrase-medial position (yellow). Paired t-tests were applied to the data of the vowels and yielded a significant effect for both positions (V1: $\mathrm{t}(24)=5.3, \mathrm{p}<.001 ; \mathrm{V} 2: \mathrm{t}(24)=7.0, \mathrm{p}<.001)$.
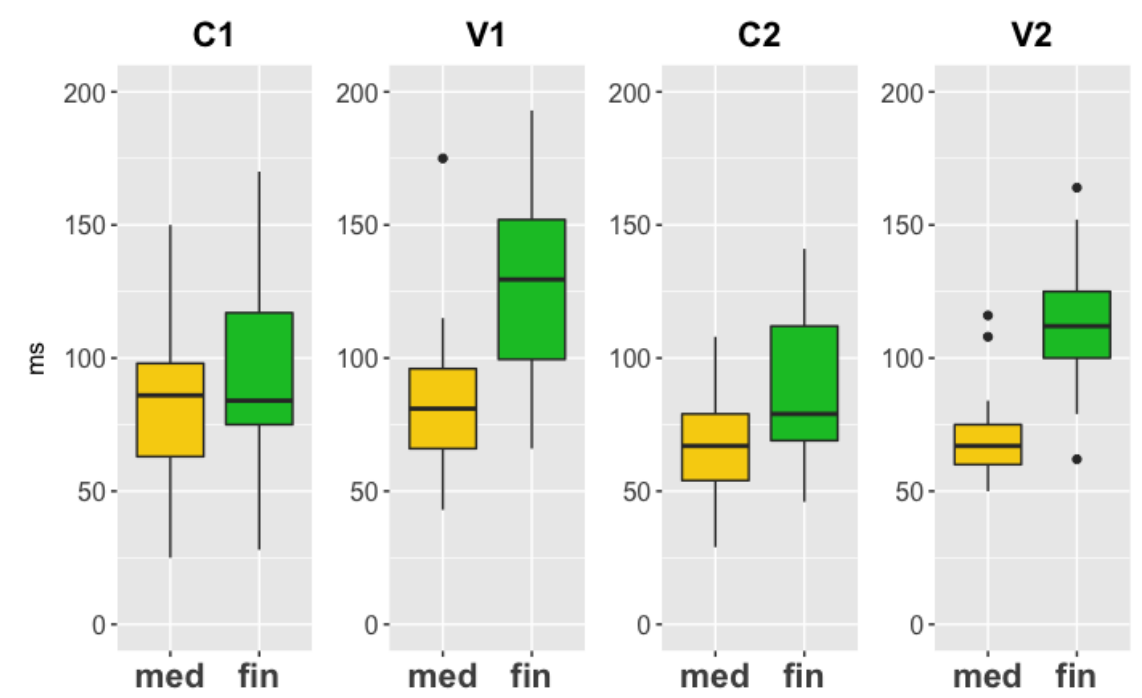

Figure 2. Duration of the segments in the penultimate syllable (C1 and V1) and the final syllable (C2 and V2) in phrase-medial position (yellow) and phrase-final position (green) across speakers, including all pairs that comprised a prosodic phrase boundary after the target word in the left-branching condition, but not in the right-branching condition $(n=25)$

The plots in Figure 2 suggest that there is less variation in the duration of the final vowel (V2) than in the duration of the preceding segments. In phrase-medial position (yellow boxes), the interquartile range becomes larger the further the segment is away from the end of the word. The data for the consonants ( $\mathrm{C} 1$ and $\mathrm{C} 2)$ tend to be negatively skewed in phrase-medial position (yellow boxes), which reflects the variation of inherent length of different consonant types (e.g., trills tend to be shorter than nasal stops). In phrase-final position (green boxes), the data for the 
consonants are positively skewed, which might result from differences in the lengthening behaviour between types of consonants. The data of the vowels (V1 and V2) are closer to a symmetric distribution. This is expected since Tswana only has phonemically short vowels.

As for the amount of lengthening, Figure 3 illustrates the increase in milliseconds (left) and percentage (right) for each segment across productions based on the mean duration of each segment in phrase-medial position in comparison to the respective mean duration in phrase-final position. The comparisons reveal an increase of $14 \mathrm{~ms}$ for the onset consonant of the penultimate syllable (C1) followed by an increase of $51 \mathrm{~ms}$ for the vowel of the penultimate syllable (V1). In the final syllable, there is an increase of $22 \mathrm{~ms}$ on the onset consonant (C2) and an increase of 43 $\mathrm{ms}$ on the vowel (V2). Thus, the increase in ms on the vowel of the penultimate syllable is slightly larger than the increase on the final vowel whereas the pattern is reversed for the consonants. The overall amount of mean increase is $65 \mathrm{~ms}$ for each of the two syllables (i.e. the sum of the means for $\mathrm{C} 1$ and $\mathrm{V} 1$ and the sum of the means for $\mathrm{C} 2$ and $\mathrm{V} 2$, respectively). As for the relative increase, the onset consonant of the penultimate syllable (C1) involves an increase of $17.1 \%$, the vowel of the penultimate syllable (V1) involves an increase of $62.2 \%$, the onset consonant of the final syllable (C2) involves an increase of 32.4\%, and the final vowel (V2) involves an increase of $62.3 \%$. Thus, in relative terms, both vowels comprise about the same amount of increase whereas the onset consonant of the final syllable (C2) comprises a larger amount of increase than the onset consonant of the penultimate syllable $(\mathrm{C} 1)$. The overall amount of relative increase is thus larger in the final syllable than in the penultimate syllable.
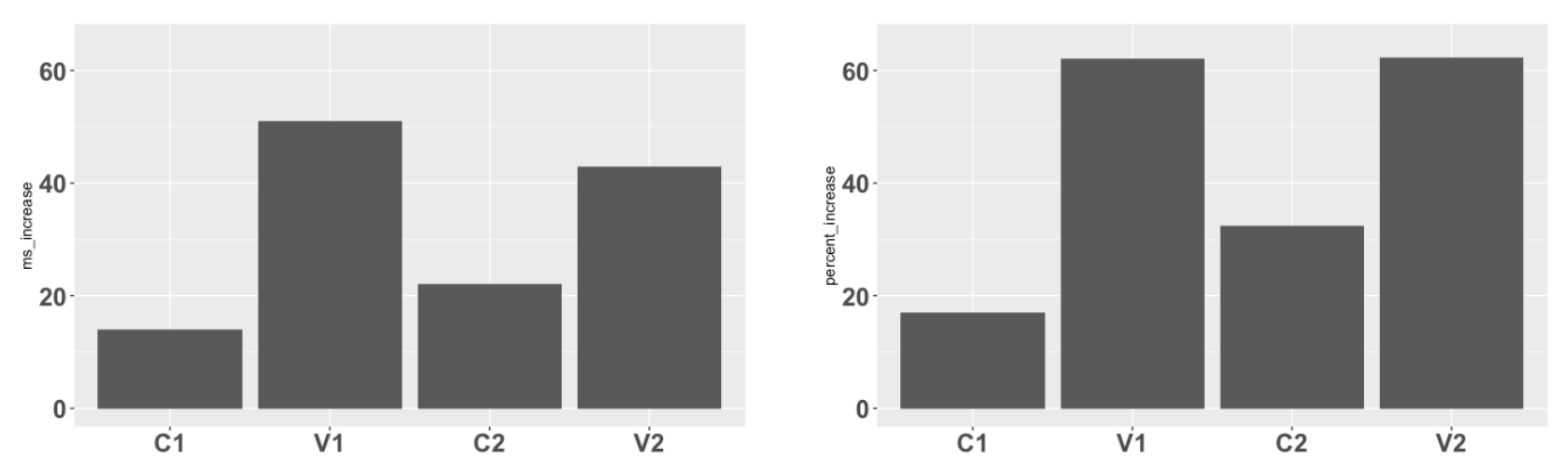

Figure 3. Increase of duration in milliseconds (left) and percentage (right) for the segments in the penultimate and final syllables based on the mean duration values of the productions in phrase-final position in comparison to the productions in phrase-medial position $(n=25)$

In sum, the results suggest that the amount of lengthening drastically increases on the vowel of the penultimate syllable, then lowers on the following consonant, and increases again on the final vowel. Both vowels show a comparable amount of lengthening. The onset consonant in the final syllable shows a larger relative increase than the one in the penultimate syllable. Thus, with regard to syllables, the relative amount of lengthening is larger in the final syllable than in the penultimate syllable.

In the auditory (qualitative) analysis, we discerned no prosodic phrasing cues in the sequences of nouns in 26 cases (18 in the left-branching and 8 in the right-branching condition; see Table 1). An open question is whether subtle lengthening cues might nevertheless exist which may have escaped our attention. In order to test this possibility, we checked those cases where we did not discern a prosodic phrasing cue in both productions from the same item by the same 
speaker. A total of five such pairs occurred in the data. A comparison of the duration values in these pairs did not suggest a subtle lengthening effect.

\subsection{Lengthening at the word level}

The analysis of lengthening before word boundaries in phrase-medial position includes all productions from the right-branching condition that did not comprise a prosodic phrase boundary after N2. A total of 53 such productions occurred in the data, yielding a larger dataset than was available for the analysis of lengthening before prosodic phrase boundaries. None of these productions comprised a boundary after the following conjunction (le 'and', which might be a proclitic; see also section 5.1). Figure 4 illustrates the duration data for the vowels of the penultimate syllable (left) and the final syllable (right). The plots suggest that the duration of the vowel in the penultimate syllable (V1) is longer than the duration of the vowel in the final syllable (V2). The difference is significant in a paired $t$-test $(t(52)=2.9, p<.01)$. The vowels of the penultimate syllable comprised a mean duration of $83 \mathrm{~ms}$ whereas the vowels of the final syllable comprised a mean duration of $73 \mathrm{~ms}$. Thus, on average, the vowels were $14 \%$ longer in the penultimate syllable. Consonants were not incorporated into this analysis because the frequency of different consonant types varied in the final and penultimate syllables. Thus, differences in the inherent duration of consonants could affect the duration difference between the consonants in the final syllable and those in the penultimate syllable.

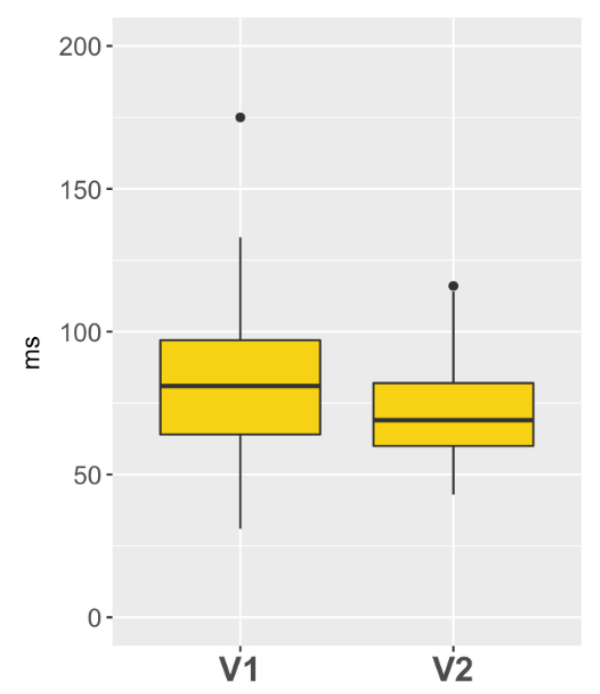

Figure 4. Duration of the vowels of the penultimate syllable (V1) and the vowels of the final syllable (V2) in the target words from the right-branching condition that did not comprise a following boundary $(n=53)$

\section{Discussion and conclusions}

As for the research questions stated in (1), the observed duration patterns suggest that both PL and FL apply in Tswana. We found lengthening in both the penultimate and the final syllables. In both syllables, the amount of lengthening was larger on the vowel than on the consonant. The abrupt increase of lengthening on both vowels suggests that the lengthening effects derive from independent mechanisms. Cross-linguistically, it has been found that the amount of FL increases towards the phrase boundary (see section 2.2) and is relatively small on the segments preceding the final rime (e.g., Schubö and Zerbian 2020 for German, Seo et al. 2019 for 
Japanese, Turk and Shattuck-Hufnagel 2007 for American English). Given these patterns, the large amount of lengthening on the vowel of the penultimate syllable suggests that this effect is not related to FL but that PL operates independently. The relatively small amount of lengthening on the onset consonant of the final syllable and the relatively large amount on the final vowel are in line with the common FL pattern in phrase-final syllables, which suggests that FL also applies in Tswana.

The present study found FL in the final syllable before a prosodic phrase boundary, but did not identify its entire domain. The amount of relative lengthening on the onset consonant in the penultimate syllable was smaller than the amount on the onset consonant in the final syllable. This difference fits the pattern of progressive lengthening (i.e. a gradual increase of lengthening towards the end of the prosodic phrase) which has been observed in connection with FL in various languages, and also on segments preceding the final syllable. Thus, the (comparatively small) amount of lengthening on the onset consonant of the penultimate syllable might be a FL effect. On the other hand, as part of the penultimate syllable, it might also be triggered by PL. Furthermore, it might be that lengthening occurs before the penultimate syllable, a possibility which was not investigated in this study. Identifying the exact domain for FL in Tswana is left open for future research.

For the Tswana variety of Shekgalagari, Hyman and Monaka (2011) report the presence of FL and the absence of PL on constituents in paused lists. In the structure that was investigated here, a pause often (though not always) followed the noun and might thus make it resemble the paused lists investigated in Shekgalagari. However, the occurrence of FL is not predicted to be restricted to this structure only, but is predicted to occur at all prosodic phrase boundaries. Moreover, we also found PL in these structures, contrary to the observation for paused lists by Hyman and Monaka (2011).

The observation that both the penultimate and final vowels undergo a large and comparable amount of lengthening raises the question as to why prior studies commonly identified PL, but not FL, as a discrete cue for prosodic phrasing in Tswana. This might be related to the relative perceptual salience of the two vowels: the penultimate vowel comprises an abrupt lengthening effect, involving a considerably larger amount of duration than the preceding segments. The final vowel also involves a relatively large amount of lengthening, but its duration does not exceed the duration of the preceding vowel (which underwent PL). As a result, it might be that listeners are more sensitive to the lengthening effect on the penultimate syllable (PL) than to the lengthening effect on the final syllable (FL). Comparing the total amount of relative lengthening for each syllable, we found that the lengthening effect was slightly stronger on the final syllable. The abrupt increase in duration on the vowel of the penultimate syllable might, however, yield an effect of relatively stronger perceptual prominence and may thus render the lengthening effect more noticeable.

The average percentage increase of lengthening found on the final vowel was $62 \%$. Compared with other languages, this amount is relatively small. For example, Schubö and Zerbian (2020) tested FL in German with a comparable design and procedure as employed here. They found an average amount of $92 \%$ for the final vowel in an open syllable. The smaller amount of FL in Tswana might result from the fact that a large amount of lengthening also occurs in the preceding syllable, which was not the case in German. 
As for the research question in (2) relating to a potential PL effect at the word level, we found that, when produced in phrase-medial position, vowels in the penultimate syllable were significantly longer than vowels in the final syllable. This pattern suggests that PL might not only apply before prosodic phrase boundaries, but also before word boundaries. On average, the difference was $10 \mathrm{~ms}$, which corresponds to $14 \%$. This difference is considerably smaller than the mean difference between vowels in the penultimate syllable produced in phrase-final position and vowels produced in phrase-medial position. The latter involved a difference of 51 $\mathrm{ms}$, corresponding to an increase of $62 \%$. These observations are in line with the patterns described by Cole (1955: 55), who refers to a "half length" for the penultimate syllable of every word and "full length" before sentence boundaries.

The analyses presented in this study are based on a limited amount of data. Thus, future research employing a larger dataset is required in order to verify the observed patterns. Furthermore, future research should address the difference between utterance-medial and utterance-final prosodic boundaries with regard to the implementation of PL and FL. Such a comparison might reveal that the lengthening effects are stronger in utterance-final position than in utterancemedial position, as has been found for some languages with regard to FL (e.g., Michelas and D'Imperio 2010 for French). Downing and Pompino-Marschall (2013) found PL and FL at final IP-boundaries in the Bantu language of Chichewa. Such a comparison was not possible based on the data gained in the present study because the utterance-final words were not controlled as to their internal syllable structure and thus showed a fair amount of variation in this regard (including sequences of consecutive vowels and a vowel and a glide, for which it is difficult to detect the segment boundary). As remarked above, future research is also required in order to test for the presence of lengthening on material preceding the penultimate syllable. Such investigations are relevant to our understanding of the implementation of lengthening before prosodic phrase boundaries as well as at the word level.

In sum, this study provides the first empirical investigation of boundary-related lengthening in Tswana, attesting to both PL and FL. PL occurs before prosodic phrase boundaries as well as before word boundaries, yet to differing degrees. FL operates on the final syllable before a prosodic phrase boundary, involving a larger amount on the final vowel than on the preceding consonant. This pattern is in line with the FL pattern observed in other languages. Given that a large increase in lengthening on the penultimate syllable has not been observed in connection with FL, we assume that PL constitutes a language-specific mechanism that applies independently. FL, on the other hand, might be a universal phenomenon, as it has been attested across languages with diverse prosodic systems, such as German (e.g., Schubö and Zerbian 2020), Japanese (e.g., Seo et al. 2019), and Tswana.

\section{Acknowledgements}

This research has been funded by the DFG (German Research Foundation), grant ZE940/3-1. We thank all speakers for their participation and Nadja Spina for assistance in the segmentation of the data. 


\section{References}

Bennett, W., M. Diemer, J. Kerford, T. Probert and T.Wesi. 2016. Setswana (South African). Journal of the International Phonetic Association 46(2): 235-246. https://doi.org/10.1017/s0025100316000050

Berkovits, R. 1994. Durational effects in final lengthening, gapping, and contrastive stress. Language and Speech 37(3): 237-250. https://doi.org/10.1177/002383099403700302

Boersma P. and Weenink D. 2019. Praat: Doing phonetics by computer. Computer program, version 6.1.05. Available online: http://www.praat.org/ (Accessed on 1 February 2019).

Cambier-Langeveld, T. 1997. The domain of final lengthening in the production of Dutch. In H. de Hoop and J. Coerts (eds.) Linguistics in the Netherlands. Amsterdam: John Benjamins. pp. 13-24. https://doi.org/10.1075/avt.14.04cam

Carlson, R., J. Hirschberg and M. Swerts. 2005. Cues to upcoming Swedish prosodic boundaries, subjective judgment studies and acoustic correlates. Speech Communication 46(3/4): 326-333. https://doi.org/10.1016/j.specom.2005.02.013

Cheng, L. and L.J. Downing. 2007. The prosody and syntax of Zulu relative clauses. SOAS Working Papers in Linguistics 15(2007): 51-63.

Cheng, L. and L.J. Downing. 2009. Where's the topic in Zulu? The Linguistic Review 26(2/3): 207-238. https://doi.org/10.1075/z.189

Cheng, L. and L.J. Downing. 2014. The problems of adverbs in Zulu. In J. Caspers, Y. Chen, W. Heeren, J. Pacilly, N.O. Schiller and E. van Zanten (eds.) Above and beyond the segments: Experimental linguistics and phonetics. Amsterdam: John Benjamins. pp. 42-55.

Cole, D.T. 1955. An introduction to Tswana grammar. Cape Town: Longman.

Creissels, D. 1998. Expansion and retraction of high tone domains in Setswana. In L. Hyman and C. Kisseberth (eds.) Theoretical aspects of Bantu tone. Stanford: Center for the Study of Language and Information. pp. 133-194.

Downing, L.J. 2011. The prosody of 'dislocation' in selected Bantu languages. Lingua 121(5): 772-786. https://doi.org/10.1016/j.lingua.2010.11.006

Downing, L.J. and L.M. Hyman. 2016. Information structure in Bantu. In C. Féry and S. Ishihara (eds.) Handbook of information structure. Oxford: Oxford University Press. pp. 790-813. https://doi.org/10.1093/oxfordhb/9780199642670.013.010

Downing, L.J. and A. Mtenje. 2011. Prosodic phrasing of Chichewa relative clauses. Journal of African Languages and Linguistics 32(1): 65-112. https://doi.org/10.1515/jall.2011.003 
Downing, L.J. and B. Pompino-Marschall. 2013. The focus prosody of Chichewa and the Stress-Focus constraint: A response to Samek-Lodovici (2005). Natural Language and Linguistic Theory 31(3): 647-681. https://doi.org/10.1007/s11049-013-9192-x

Gussenhoven, C. and A.C.M. Rietveld. 1992. Intonation contours, prosodic structure and preboundary lengthening. Journal of Phonetics 20(3): 283-303. https://doi.org/10.1016/s0095$\underline{4470(19) 30636-9}$

Hyman, L.M. 2013. Penultimate lengthening in Bantu: Analysis and spread. In B. Bickel, L.A. Grenoble, D. Peterson and A. Timberlake (eds.) Language typology and historical contingency: In honor of Johanna Nichols. Amsterdam: John Benjamins. pp. 309-330. https://doi.org/10.1075/tsl.104.14hym

Hyman, L.M. and K.C. Monaka. 2011. Tonal and non-tonal intonation in Shekgalagari. In S. Frota, G. Elordieta and P. Prieto (eds.) Prosodic categories: Production, perception and comprehension. Berlin: Springer. pp. 269-288. https://doi.org/10.1007/978-94-007-0137-3_12

Jones, J., J.A. Louw and J.C. Roux. 2001a. Perceptual experiments on queclaratives in Xhosa. South African Journal of African Languages, supplement 36: 19-32. https://doi.org/10.1080/02572117.2003.10587220

Jones, J., J.A. Louw and J.C. Roux. 2001b. Queclaratives in Xhosa: An acoustic analysis. South African Journal of African Languages, supplement 36: 3-18. https://doi.org/10.1080/02572117.2003.10587220

Kanerva, J.M. 1990. Focus and phrasing in Chichewa phonology. New York: Garland.

Katsika, A. 2016. The role of prominence in determining the scope of boundary-related lengthening in Greek. Journal of Phonetics 55: 149-181. https://doi.org/10.1016/j.wocn.2015.12.003

Kentner, G. and C. Féry. 2013. A new approach to prosodic grouping. The Linguistic Review 30(2): 277-311. https://doi.org/10.1515/tlr-2013-0009

Krull, D. 1997. Prepausal lengthening in Estonian: Evidence from conversational speech. In I. Lehiste and J. Ross (eds.) Estonian prosody: Papers from a symposium. Tallinn: Institute of the Estonian Language. pp. 136-148. https://doi.org/10.2307/417159

Lindblom, B. 1968. Temporal organisation of syllable production. Speech Transmission Laboratory - Quarterly Progress and Status Report 9(2): 1-5.

Lindblom, B. 1978. Final lengthening in speech and music. In E. Garding, G. Bruce and R. Bannert (eds.) Nordic prosody. Lund: Lund University Department of Linguistics. pp. 85-102.

Michelas A. and M. D'Imperio. 2010. Durational cues and prosodic phrasing in French: Evidence for the intermediate phrase. Paper presented at the $5^{\text {th }}$ International Conference on Speech Prosody. Chicago, IL, 11-14 May 2010. 
Nakai, S., S. Kunnari, A. Turk, K. Suomi and R. Ylitalo. 2009. Utterance-final lengthening and quantity in Northern Finnish. Journal of Phonetics 37(1): 29-45. https://doi.org/10.1016/j.wocn.2008.08.002

Petrone, C., H. Truckenbrodt, C. Wellmann, J. Holzgrefe-Lang, I. Wartenburger and B. Höhle. 2017. Prosodic boundary cues in German: Evidence from the production and perception of bracketed lists. Journal of Phonetics 61: 71-92. https://doi.org/10.1016/j.wocn.2017.01.002

Schubö, F. and S. Zerbian. 2020. Phonetic content and phonological structure affect preboundary lengthening in German. Paper presented at the 10th International Conference on Speech Prosody. Tokyo, Japan, 25-28 May 2020. https://doi.org/10.21437/speechprosody.2020-23

Seo, J., S. Kim, H. Kubozono and T. Cho. 2019. Interaction between rhythmic structure and preboundary lengthening in Japanese. In S. Calhoun, P. Escudero, M. Tabain and P. Warren (eds.) Proceedings of the 19th International Congress of Phonetic Sciences, Melbourne, Australia 2019. Canberra: Australasian Speech Science and Technology Association Inc. pp. 637-641.

Silverman, K.E.A. 1990. The separation of prosodies: Comments on Kohler's paper. In J. Kingston and M. Beckman (eds.) Papers in laboratory phonology I: Between the grammar and physics of speech. Cambridge: Cambridge University Press. pp. 139-151. https://doi.org/10.1017/s0952675700001895

Turk, A. and S. Shattuck-Hufnagel. 2007. Multiple targets of phrase-final lengthening in American English words. Journal of Phonetics 35(4): 445-472. https://doi.org/10.1016/j.wocn.2006.12.001

Turk, A., S. Nakai and M. Sugahara. 2006. Acoustic segment durations in prosodic research: A practical guide. In A. Steube (ed.) Language, context and cognition: Methods in empirical prosody research. Berlin: Mouton de Gruyter. pp. 445-472. https://doi.org/10.1515/9783110914641.1

Vaissière, J. 1983. Language-independent prosodic features. In A. Cutler and D.R. Ladd (eds.) Prosody: Models and measurements. Berlin: Springer. pp. 53-66. https://doi.org/10.1007/978$\underline{3-642-69103-4 \_5}$

White, L.S. 2002. English Speech Timing: A Domain and Locus Approach. Unpublished PhD dissertation, University of Edinburgh.

Zeller, J., S. Zerbian and T. Cook. 2017. Prosodic evidence for syntactic phrasing in Zulu. In J. van der Wal and L.H. Hyman (eds.) The conjoint/disjoint alternation in Bantu. Berlin: Mouton de Gruyter. pp. 295-328. https://doi.org/10.1515/9783110490831-011

Zerbian, S. 2007. Phonological phrasing in Northern Sotho. The Linguistic Review 24(2/3): 233-262. https://doi.org/10.1515/tlr.2007.009 
Zerbian, S. 2011. A guide to tones in Tswana locatives. South African Journal of African Languages 31(2): 254-264. https://doi.org/10.1080/02572117.2011.10587369

Zerbian, S. 2017. Sentence intonation in Tswana. In L.J. Downing and A. Rialland (eds.) Intonation in African tone languages. Berlin: Mouton de Gruyter. pp. 393-434. https://doi.org/10.1515/9783110503524-012 


\section{APPENDIX}

Contexts and target sentences with translations:

(1)

Dineo o rulaganya moletlo wa letsatsi la gagwe la matsalo. O setse a laleditse ditsala dingwe. Jaanong o ipotsa gore ke mang yo mongwe gape yo a ka mo laletsang. Dineo o a nagana: 'Dineo is organising a party to celebrate his birthday. He has already invited many friends. Now he is wondering who else he would like to invite. Dineo is thinking:'

Ke tla laletsa Katlego kgotsa Naledi le Lorato.

Ke tla laletsa Katlego kgotsa Naledi le Lorato.

'I'll invite Katlego or Naledi and Lorato.'

(2)

Bonolo o batla go etela ditsala tsa gagwe fa sekolo se tswa, fela ga a na nako. Jaanong o ipotsa gore a ka etela mang mo ditsaleng tsa gagwe. Bonolo o a nagana:

'Bonolo wants to visit her friends after school, but she doesn't have much time. Now she is wondering which of her friends she should visit. Bonolo is thinking:'

Ke tla etela Puleng kgotsa Lorato le Masego.

Ke tla etela Puleng kgotsa Lorato le Masego.

'I'll visit Puleng or Lorato and Masego.'

(3)

Tebogo o batla go thusa ditsala tsa gagwe ka tirogae, fela ga a na nako. Jaanong o ipotsa gore a ka thusa mang mo ditsaleng tsa gagwe. Tebogo o a nagana:

'Tebogo wants to help her friends doing their homework. But she doesn't have much time. Now she's wondering which of her friends she should help. Tebogo is thinking:'

Ke tla thusa Bontle kgotsa Lesedi le Refilwe.

Ke tla thusa Bontle kgotsa Lesedi le Refilwe.

'I'll help Bontle or Lesedi and Refilwe.'

(4)

Baithuti bangwe ba ne ba dira metlae kwa sekolong. Mogokgo ga a itse gore e ne e le kakanyo ya ga mang. Jaanong o ipotsa gore ke mang yo o tshwanetsweng ke go itewa. Mogokgo o a nagana:

'Some pupils have played a prank at school. The headmaster does not know whose idea it was. Now she is wondering who she should scold. The headmaster is thinking:'

Ke tla itaya Neo kgotsa Tshenolo le Kano.

Ke tla itaya Neo kgotsa Tshenolo le Kano.

'I'll scold Neo or Tshenolo and Kano.'

(5)

Ditsala tsa ga Tumelo di iphitlhile mme Tumelo o tshwanetse go bona mo ba iphitlhileng teng. Jaanong o ipotsa gore a simolole ka go batla mang pele. Tumelo o a nagana: 
'Tumelo's friends are hiding and Tumelo is supposed to find them. Now she is wondering who to search for first. Tumelo is thinking:'

Ke tla batla Lesedi kgotsa Kopano le Laone.

Ke tla batla Lesedi kgotsa Kopano le Laone.

'I'll look for Lesedi or Kopano and Laone.'

(6)

Fa ba ntse ba tshameka mo tshimong, mongwe o ne a gobala mme Fenyang a tshwanelwa ke go batla thuso. Jaanong o ipotsa gore a ka lata mang. Fenyang o a nagana:

'While playing in the garden, someone got hurt and Fenyang has to get help. Now she is wondering who she should get. Fenyang is thinking:'

Ke tla lata Kenosi kgotsa Karabo le Thabo.

Ke tla lata Kenosi kgotsa Karabo le Thabo.

'I'll fetch Kenosi or Karabo and Thabo.'

(7)

Sengwe se ne se utswitswe kwa sekolong. Morutabana o batla go botsolotsa bangwe ba baithuti. Jaanong o ipotsa gore ke mang yo a ka tswang a itse sengwe. Morutabana o a nagana:

'Something was stolen from the school. The teacher wants to question some of the pupils. Now he is wondering who might know something. The teacher is thinking:'

Ke tla botsolotsa Thapelo kgotsa Bonolo le Kgosi.

Ke tla botsolotsa Thapelo kgotsa Bonolo le Kgosi.

'I'll interrogate Thapelo or Bonolo and Kgosi.'

\section{(8)}

Moagisanyi wa ga Tshepang o mo kopile gore a mo tseele bangwe ba bana ba bona kwa sekolong. Jaanong o ipotsa gore a ka tsaya ba ba feng mo baneng bao. Tshepang o a nagana:

'Tshepang's neighbour asked her to pick up some of their children from school. Now she is wondering which of the children she could pick up. Tshepang is thinking:'

Ke tla tsaya Tshenolo kgotsa Thapelo le Tuelo.

Ke tla tsaya Tshenolo kgotsa Thapelo le Tuelo.

'I'll pick up Tshenolo or Thapelo and Tuelo.'

(9)

Mongwe o sentse koloi ya ga rre Mothibi. O dumela gore e ka tswa e le bana ba baagisanyi ba gagwe ba ba dirileng se. Jaanong o ipotsa gore a ka latofatsa mang. Rre Mothibi o a nagana:

'Someone damaged Mr. Mothibi's car. He believes that his neighbours' kids might have done that. Now he is wondering who he could accuse. Mr. Mothibi is thinking:

Ke tla latofatsa Khumo kgotsa Thabo le Modise.

Ke tla latofatsa Khumo kgotsa Thabo le Modise.

'I'll accuse Khumo or Thabo and Modise.' 
(10)

Kabelo o batla go leka mogala wa gagwe wa letheka o mošwa. Jaanong o ipotsa gore a ka leletsa mang. Kabelo o a nagana:

'Kabelo wants to try out her new cellphone. Now she is wondering who she could call. Kabelo is thinking:'

Ke tla leletsa Kagiso kgotsa Kano le Leruo.

Ke tla leletsa Kagiso kgotsa Kano le Leruo.

'I'll call Kagiso or Kano and Leruo.'

(11)

Ditsala tsa ga Paseka di batla gore a tsamaye le bona, fela ba tshwanetse go ya kwa dintlheng tse di farologaneng. Jaanong o ipotsa gore o tla tsamaya le mang. Paseka o a nagana:

'Paseka's friends want him to accompany them, but they have to go in different directions. Now he is wondering who he will accompany. Paseka is thinking:'

Ke tla tsamaya le Thato kgotsa Khumo le Kabo.

Ke tla tsamaya le Thato kgotsa Khumo le Kabo.

'I'll accompany Thato or Khumo and Kabo.'

(12)

Morutabana o nagana gore baithuti bangwe ga ba a dira tirogae ya bona ka bobona. Jaanong o ipotsa gore a ka kgalema mang. Morutabana o a nagana:

'The teacher is thinking that some pupils did not do their homework themselves. Now he is thinking who he should warn. The teacher is thinking:'

Ke tla kgalema Karabo kgotsa Modi le Mpho.

Ke tla kgalema Karabo kgotsa Modi le Mpho.

'I will warn Karabo or Modi and Mpho.' 